\title{
Prospects for the use of solar energy to accelerate the hardening of concrete in the construction of monolithic structures in Russia
}

\author{
David A. Sarkisov ${ }^{1, *}$, Boris V. ZHadanovskii ${ }^{1}$, Sergey A. Sinenko ${ }^{1}$, and Maksim K. Esenov ${ }^{1}$ \\ ${ }^{1}$ Moscow State University of Civil Engineering, Yaroslavskoe shosse, 26, Moscow, 129337, Russia
}

\begin{abstract}
This article addresses the issue of solving the problem of using the solar energy, that allows decreasing of the unit costs, or even avoiding using of the traditional energy resources for performance of the concrete in the southern regions of Russian. Researches that were carried out allow developing more contemporary methods of monolithic construction's concrete curing. Various types of methods of solar energy using in case to produce precast concrete or reinforced concrete items found vast distribution and implementation in construction industry.
\end{abstract}

\section{Introduction}

Power consumption for domestic and industrial needs (hot water supply, indoor heating, desalination, pool heating, indoor air conditioning) decreased by $20 \%$ due to the renewable energy sources applying. Electric power production increased by $18 \%$. Vast usage of renewable energy sources allowed reducing the import by $30 \%$ over these years to these countries of oil and gas, and also to decrease carbon dioxide emissions into the air significantly.

Producing of concrete, as the most vital material for construction, related to loses of significant amount of fuel and energy resources in the form of low-grade heat. 12 million tons of the oil equivalent is spent on production of precast concrete items, during the erection of the monolithic constructions - more then 6 million [1].

$35 \%$ of the total fuel and energy consumption falls on areas with beneficial conditions for the solar energy using [2].

Contradictions inherent in the needs of the production of heat carrying agent, and intermittency in solar energy supply limit the area of its practical application at the construction industry enterprises. With a high (20-30\%) share of energy costs in the cost price of construction products low prices continue to persist energy resource, restraining construction organizations in the development of alternative energy sources [3].

\section{Materials and methods}

There is a list of methods, that can be used to erect a monolithic construction:

\footnotetext{
* Corresponding author: dav9.9@mail.ru
} 
Direct solar energy heating,

Accumulation of the solar energy using the energy-intensive materials,

Concentration of the solar radiation flow density,

Balancing a system, that combines the use of known technologies of the heat carrying agents in the active solar energy system.

The most available mean of the effective usage of a new type of energy is the acceleration of concrete hardening based on the "greenhouse effect (carbon dioxide)" principle [4].

The main condition for achieving of the active solar energy system in which the "greenhouse effect (carbon dioxide)" is exhibited is the fencing an optically transparent film that can pass short-wave radiation and delay long-wave radiation closely around the concrete structure.

To achieve this, various technological and technical methods are used, such as creating a protective vapor-water-tight shield over the concrete, laying a thermal insulation coating on its surface during the maximum heating by solar radiation, preheating the concrete mixture and further isothermal aging of the concrete under the influence of solar energy:

Thermal insulation of the walls of formwork forms with the installation of single - or multi-layer translucent plates over the concrete, one of which can be with a selective coating; [5].

Item placement under the standard device of the greenhouse effect (carbon dioxide) type

Polymer polyethylene terephthalate, polyethylene, polyvinyl chloride films are used as a coating.

The great advantage of polymer films is the ability to cover monolithic structures of various shapes, shapes and orientations. Horizontal and inclined structures - roads, irrigation channels, airfield surfaces, industrial facilities sites-are directly covered with a film [6].

During the construction of residential buildings in sliding formwork, the coating of films is placed along the entire external contour of the structure, in the area of the external flying scaffolding.

Construction's roof slab production represents practical interest during erection of the building whit the lift-slab method. For this purpose entire panel is prepared on the inter-floor slab accounting the film's overlapping on the end sides. After the concrete pouring and surface's finishing, constructions are covered with the film and leaved until the required strength gaining is reached.

The strength gaining characterized considering the following parameters:

The first day $40-60 \% \mathrm{R} 28$,

The second $60-75 \%$ R 28 ,

The third 70-90\% R28, where R28 - is the compressive resistance of concrete at the age of 28 days.

Solar radiation - is a specific type of energy, and its thermal effect on concrete occurs only during the daytime. It seems necessary to accumulate it in energy-intensive materials. It is also important to maintain a uniform thermal requirement for a long time period both in the device and concrete. Paraffin, cycloparaffin-containing substances, various salts, and eutectic mixtures can be accepted, as a energy-intensive material [7].

The input of solar radiation is periodic, and the process of precast items producing is carried out in conditions of constant consumption of the heat-carrying agent [7].

At the present stage of the alternative type of energy development, short-term and daily accumulation is the main interest, when the components of concrete, water and aggregate are heated, as the most energy-intensive part of the material for the preparation of preheated concrete mixes.

Researches showed that it is possible to heat up to $68 \mathrm{C}$ a layer of gravel with a height of $1.5 \mathrm{~m}$ in 7 hours by the solar radiation flow with the density of $950-1000 \mathrm{~W} / \mathrm{m} 2$, with the help of air collectors in a silo-type bunker [8]. 


\section{Results}

To cure a free-standing concrete structures (industrial enterprise foundations, pipes), it is rational to use a combined installation. It consists of heat-insulated walls, heat accumulators made in the form of removable sectional tanks, a multi-piece roof made of one or two plates transparent to heat rays, solar radiation reflectors and a heat-insulated part.

During the day, the concentrator, which is an integral part of the roof, reflects radiant energy and increases its flow density of on the translucent part of the device, at night the roof is closed. During this period, the concentrator acts as a heat-reflecting screen, and the thermal insulation prevents the accumulated energy losses. During the concreted pouring of the structure, the batteries are charged with thermal energy; after the concrete mixture is laid, the structure is placed under the device and the heat treatment of the concrete begins.

If necessary, for preheating the heat-accumulating material and the entire volume, the setting can be connected to stationary energy sources, which represents the interest for the concrete in conditions of positive and negative temperatures.

In order to increase the reusability of the formwork, it is allowed to remove the formwork, when concrete reaches the stripping strength and maintain the concrete structure until the required strength is obtained.

The thin-walled cylindrical concrete construction is expedient to perform with the use of heating formwork. Structurally, it consists of a heat-sensitive material, a translucent fence, and a solar radiation concentrator. The radiated part of the structure (eastern, southern, western) of the heater - by direct sunlight, the shadow part (northern) - by reflecting them on the formwork, with a concentrator. This type of devices are designed for the construction of cooling towers, pipes, silos, tanks.

Shows the data on the study of the growth kinetics of the concrete strength when it is kept under the film. The main period of concrete strength occurs in the first 1-3 days. The adding of a hardening accelerator into the concrete composition makes it possible to reduce the duration of holding the concrete to the required strength by 2 times (table 1).

Table 1. Method of holding freshly placed concrete.

\begin{tabular}{|c|c|c|c|c|c|c|c|c|c|c|}
\hline \multicolumn{6}{|c|}{ Under the film } & \multirow{2}{*}{\multicolumn{2}{|c|}{ 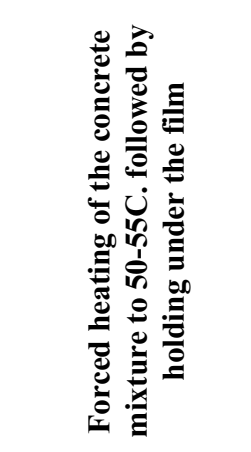 }} & \multirow{2}{*}{\multicolumn{2}{|c|}{ 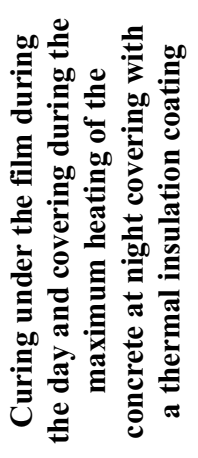 }} & \multirow[b]{2}{*}{ 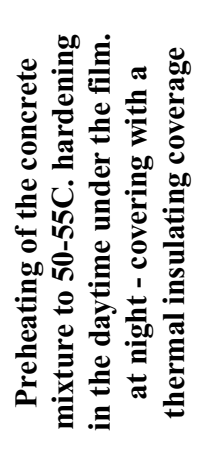 } \\
\hline & \multicolumn{2}{|c|}{ 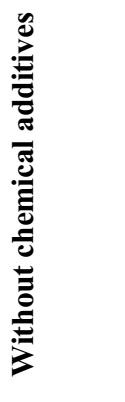 } & & \multicolumn{2}{|c|}{ 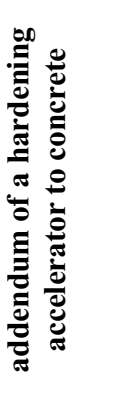 } & & & & & \\
\hline \multicolumn{11}{|c|}{ Duration of curing. day } \\
\hline 1 & 2 & 3 & 1 & 2 & 3 & $\begin{array}{c}0.5 \\
\text { (concrete } \\
\text { curing during } \\
\text { the daylight } \\
\text { hours from } 9 \\
\text { to } 18 \text { hours) }\end{array}$ & 1 & 1 & 2 & 1 \\
\hline
\end{tabular}




\begin{tabular}{|l|l|l|l|l|l|l|l|l|l|l|}
\cline { 2 - 8 } 60 & 75 & 83 & 70 & 91 & 100 & 51 & 74 & 72 & 84 & 88 \\
\hline
\end{tabular}

The maximum heating of concrete by solar radiation occurs in 17-18 hours. The duration of isothermal curing during the day is increased by covering with a thermal insulation coating. Protection of the concrete heated by solar radiation with a thermal insulation coating allows gaining up to $10 \%$ of R2 28 in one day.

The using of a combined method of thermal affect on concrete hardening, including forced steam or electric heating of the concrete mixture, or the entire concrete structure, and further isothermal curing under the solar radiation affect, represents a practical interest. The solar energy passed through the transparent film accumulates in the concrete, maintaining a uniform temperature and humidity regime during daylight hours.

During the pouring of a concrete mixture preheated to $50-55 \mathrm{C}$ into the formwork and then curing the concrete under a transparent film during daylight hours (from 9 to 18 hours), it is possible to gain the strength of $51 \% \mathrm{R} 28$, and at the one day - 74\% R28. This method also makes it possible to implement batch manufacturing technology in the conditions of a construction site or on open summer landfills.

The estimating of the concrete structure, after curing under the polymer film during 1-3 days., then up to 28 days was made without maintenance in a high-temperature dry conditions, for frost resistance and water resistance in comparison with concrete maintained in a normal hardening chamber. As a result of the studies, no significant differences in the properties of concrete were revealed.

Experimental studies were conducted to determine optimal time for the beginning and end of heat treatment, time for halting concrete care. The most optimal time to prevent concrete care is a time when environment temperature and concrete temperatures are equal or have smaller change. In this case, the relative heating-cooling temperature transition smoothness implements. During the concrete mixture pouring into the formwork at 9-20 am and the beginning of the thermal effect on the concrete at this time, it is expedient to perform the formwork removal at 6-9 am. The total duration of concrete curing is 21-22 hours. In the evening, from 21 to 24 hours, the surface layers of concrete begin getting cool. In order to protect the concrete from heat accumulation, there are techniques for maintaining a constant temperature regime. (Table 2).

Table 2. Evaluation of the efficiency of solar energy using for the concrete heat treatment.

\begin{tabular}{|c|c|c|c|c|c|}
\hline 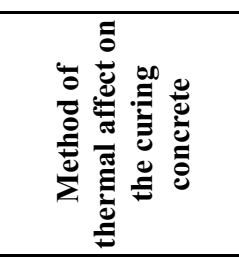 & 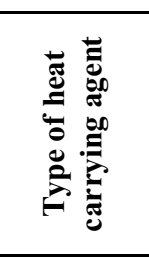 & 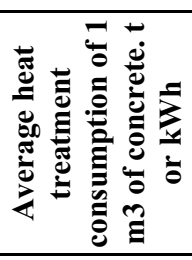 & 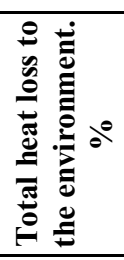 & 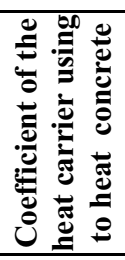 & \\
\hline $\begin{array}{l}\text { steam curing in } \\
\text { the steam } \\
\text { chamber }\end{array}$ & Steam & 0.75 & $40-50$ & 0.25 & $3-4$ \\
\hline $\begin{array}{l}\text { Electrothermo- } \\
\text { treatment of } \\
\text { concrete }\end{array}$ & Electricity & $80-200$ & $10-45$ & 0.5 & 2 \\
\hline $\begin{array}{l}\text { Preliminary } \\
\text { steam heating of } \\
\text { the concrete } \\
\text { mixture }\end{array}$ & Steam & 0.1 & $15-25$ & 0. & 2 \\
\hline
\end{tabular}




\begin{tabular}{|l|l|c|c|c|c|}
\hline $\begin{array}{l}\text { Preliminary } \\
\text { electric heating } \\
\text { of the concrete } \\
\text { mix }\end{array}$ & Electricity & $50-60$ & $10-20$ & 0.65 & 2 \\
\hline $\begin{array}{l}\text { Concrete heat } \\
\text { treatment in the } \\
\text { active solar } \\
\text { energy system }\end{array}$ & $\begin{array}{c}\text { Solar } \\
\text { energy }\end{array}$ & - & 30 & 0.55 & 1 \\
\hline
\end{tabular}

\section{Conclusions}

The usage of a new technology of concrete hardening acceleration using solar energy can actually reduce the consumption of traditional heat carriers by $50-60 \%$ annually in the manufacture of precast concrete products and the construction of monolithic structures. For this purpose, the technical documentation of the inventory device, in which the heat treatment of concrete structures can be carried out, was developed. The dimension instability of the solar device allows it to cure concrete products or groups of them that are similar in external dimensions.

\section{References}

1. W. Max, L. Sang Hoon, H. Tianzhen, C. Brian, M. Lucy, H. Bob, G. Alea, Advances in Applied Energy 2, 100018 (2021) https://doi.org/10.1016/j.adapen.2021.100018

2. A. Buscemi, D. Panno, G. Ciulla, M. Beccali, V. Lo Bramo, Energy Conversion and Management 166, 719-734 (2018) https://doi.org/10.1016/j.enconman.2018.04.075

3. B. Benkhadda, M. Bouzidi, G. Salim, Constraction and Building Materials 49, 511-518 (2013) https://doi.org/10.1016/j.conbuildmat.2013.08.085

4. M. Adio, C. Manila, T. Luigi, Applied Energy 250, 1023-1035 (2019) https://doi.org/10.1016/j.apenergy.2019.05.090

5. H. Nils, G. Christopher, B. Juan, I. Alberto Crespo, S. Geir, B. Pal, B-R/ Pablo, C. Nicolas, Journal of Energy Storage 224, $100735 \quad$ (2019) https://doi.org/10.1016/j.est.2019.04.009

6. P. Mukundjee, P. Biranchi Narayana, M. Ipsita, Engineering Science and Technology, an International Journal 24, 1-10 (2021) https://doi.org/10.1016/j.jestch.2020.11.009

7. K. Laveet, M. Hasanuzzaman, N.A. Rahim, Energy Conversion and Management 195, 885-908 (2019) https://doi.org/10.1016/j.enconman.2019.05.081

8. Y. Mai, Z. Xuelai, Z. Xinchen, L. Biao, W. Xiang, L. Xiangwei, Journal of Energy Storage 35, 102246 (2021) https://doi.org/10.1016/j.est.2021.102246 